\title{
The Amygdala Modulates Memory Consolidation of Fear-Motivated Inhibitory Avoidance Learning But Not Classical Fear Conditioning
}

\author{
Ann E. Wilensky, Glenn E. Schafe, and Joseph E. LeDoux \\ W. M. Keck Foundation Laboratory of Neurobiology, Center for Neural Science, New York University, \\ New York, New York, 10003
}

\begin{abstract}
Although the lateral and basal nuclei of the amygdala are believed to be essential for the acquisition of Pavlovian fear conditioning, studies using post-training manipulations of the amygdala in the inhibitory avoidance learning paradigm have recently called this view into question. We used the $\mathrm{GABA}_{\mathrm{A}}$ agonist muscimol to functionally inactivate these nuclei immediately after single-trial Pavlovian fear conditioning or single-trial inhibitory avoidance learning. Immediate post-training infusions of muscimol had no effect on Pavlovian conditioning but produced a
\end{abstract}

dose-dependent effect on inhibitory avoidance. However, pretraining infusions dose-dependently disrupted Pavlovian conditioning. These findings indicate that the amygdala plays an essential role in the acquisition of Pavlovian fear conditioning and contributes to the modulation of memory consolidation of inhibitory avoidance but not of Pavlovian fear conditioning.

Key words: muscimol; memory; acquisition; consolidation; amygdala; inhibitory avoidance
In Pavlovian or classical fear conditioning, a neutral conditioned stimulus (CS) acquires the capacity to elicit defensive responses after association with a noxious unconditioned stimulus (US). Considerable progress has been made in identifying the neural pathways that underlie this type of learning. Lesion, tract tracing, and electrophysiological studies collectively suggest that fear conditioning involves the transmission of sensory information about the CS and US to the lateral nucleus of the amygdala (LA), where alterations in synaptic transmission are thought to encode the key aspects of the learning (LeDoux et al., 1990; Romanski et al., 1993; Maren and Fanselow, 1996; Quirk et al., 1997; LeDoux, 2000).

Although it is widely accepted that the plasticity underlying Pavlovian fear learning takes place in the amygdala, questions have been raised about the validity of this view (McGaugh et al., 1995; Cahill et al., 1999). Lesions of the amygdala made after training, especially after a delay, result in partial retention of fear-motivated instrumental learning tasks, such as inhibitory avoidance (Liang et al., 1982; Parent et al., 1995). Additionally, various pharmacological manipulations of the amygdala immediately after training have been shown to modulate the strength of inhibitory avoidance training (Dickinson-Anson et al., 1993; Liang et al., 1994; Dickinson-Anson and McGaugh, 1997; Izquierdo et al., 1997; Packard and Teather, 1998). Particularly important are findings that administration of drugs that impair Pavlovian fear conditioning when administered before training, such as the $\mathrm{GABA}_{\mathrm{A}}$ agonist muscimol or the NMDA receptor antagonist AP-5 (Liang et al., 1994; Maren et al., 1996b; Muller et al., 1997; Wilensky et al., 1999), impairs memory consolidation of inhibitory avoidance learning when given after training (Brioni et al., 1989; Castellano and McGaugh, 1990; Izquierdo et al., 1997; Zanatta et al., 1997). Consequently, it can be argued that conclusions drawn from studies using pre-training infusions of drugs are inherently confounded because of the likelihood that these drugs also affect amygdala function immediately after training. Thus, results of studies using

Received April 21, 2000; revised June 27, 2000; accepted June 28, 2000.

This research was supported in part by National Institute of Mental Health Grants RO1 MH46516, KO2 MH00956, and R37 MH38774 and by a grant from the W. M. Keck Foundation to New York University. We thank Karim Nader for helpful comments about this manuscript and Nicole Nadel and Annemieke Schoute for assistance with the histology.

A.E.W. and G.E.S. contributed equally to this work.

Correspondence should be addressed to Dr. Joseph E. LeDoux, Center for Neural Science, New York University, 4 Washington Place, Room 809, New York, NY 10003. E-mail: ledoux@cns.nyu.edu.

Copyright (c) 2000 Society for Neuroscience $0270-6474 / 00 / 207059-08 \$ 15.00 / 0$ inhibitory avoidance learning procedures have been used to support the view that the amygdala is not the site of acquisition for fear learning but rather a region that serves to modulate the strength of memory storage in other brain areas (McGaugh et al., 1995; Roozendaal et al., 1996; Cahill and McGaugh, 1998). Although a recent report from our laboratory attempted to address this issue by using post-training infusions of muscimol in Pavlovian conditioning (Wilensky et al., 1999), that study used multiple conditioning trials, which confounded training time and consolidation and may have obscured any potential effects of post-training inactivation.

In the present study, we evaluated the possibility that pharmacological manipulations of the amygdala differentially affect memory consolidation of Pavlovian fear conditioning and inhibitory avoidance learning. We infused the $\mathrm{GABA}_{\mathrm{A}}$ agonist muscimol bilaterally into the LA and adjacent areas either before or immediately after single-trial Pavlovian fear conditioning. Additionally, we directly compared the effects of post-training infusions of muscimol on single-trial inhibitory avoidance learning and Pavlovian fear conditioning.

\section{MATERIALS AND METHODS}

Subjects. Subjects were adult male Sprague Dawley rats obtained from Hilltop Labs (Scottdale, PA). Rats were housed individually in plastic Nalgene cages (Nalge Nunc International, Rochester, NY) and maintained on a $12 \mathrm{hr}$ light/dark cycle. Food and water were provided ad libitum throughout the experiment.

Surgery. Rats were given intra-amygdala cannula implants as previously described (Wilensky et al., 1999). Briefly, rats were anesthetized with sodium pentobarbital $(40 \mathrm{mg} / \mathrm{kg}$, i.p.), treated with atropine sulfate $(0.4$ $\mathrm{mg} / \mathrm{kg}$ ), and given buprenorphine HCL $(0.02 \mathrm{mg} / \mathrm{kg}$, s.c.) or ketoprofen (2 $\mathrm{mg} / \mathrm{kg}$, i.m.) as an analgesic. Using a stereotaxic frame, guide cannulas (22 gauge; Plastics One, Roanoke, VA), fitted with internal cannulas that extended out $1.5 \mathrm{~mm}$, were positioned just above the LA using coordinates from Paxinos and Watson (1986): $2.8 \mathrm{~mm}$ posterior to bregma, $5.3 \mathrm{~mm}$ lateral to the midline, and $8.0 \mathrm{~mm}$ ventral to the skull surface. The guide cannulas were fixed to screws in the skull using cranioplastic cement (Plastics One), and internal cannulas were replaced with dummy cannulas, cut $0.5 \mathrm{~mm}$ longer than the guides, to prevent clogging. All procedures were conducted in accordance with the National Institutes of Health Guide for the Care and Use of Experimental Animals and were approved by the New York University Animal Care and Use Committee.

Intracranial infusions. Rats were held in the experimenter's lap while dummy cannulas were replaced with 28 gauge infusion cannulas attached to $1.0 \mu \mathrm{l}$ Hamilton (Reno, NV) syringes via polyurethane tubing. The tubing was back-filled with sesame oil, with a small air bubble separating the oil from the drug. Drugs were infused bilaterally by an infusion pump, and cannulas were left in place for an additional $1 \mathrm{~min}$ after infusion to allow diffusion of the drug away from the cannula tip before dummy 
cannula replacement. A total amount of $0.5 \mu \mathrm{l}$ of drug or vehicle was infused into each amygdala. This amount was chosen on the basis of autoradiographic studies of the spread of muscimol (Martin, 1991) applied to the size and structure of the target (Muller et al., 1997), as well as standard volumes used in the literature (Helmstetter and Bellgowan, 1994; Muller et al., 1997; Zanatta et al., 1997). Although the LA was the main target, the infusions also likely affected the adjacent basal nucleus. We therefore refer to the affected area as the lateral and basal amygdala (LBA).

Apparatus. Pavlovian fear conditioning and testing for contextual conditioning took place in a Plexiglas conditioning chamber with a metal grid floor (model E10-10; Coulbourn Instruments, Lehigh Valley, PA) enclosed within a sound-attenuating chamber (model E10-20). Testing for auditory fear conditioning occurred in a distinct Plexiglas chamber (ENV-001; MedAssociates, Inc, Georgia, VT) fitted with a flat black Formica floor to minimize generalization to context (Schafe et al., 1999). Inhibitory avoidance conditioning and testing took place in a Plexiglas box modeled on previously published work (Brioni et al., 1989), which was divided into two compartments. The white-walled, brightly lit starting compartment was separated from the black-walled, dark shock compartment by a black Formica divider containing an upward sliding door.

Habituation, auditory fear conditioning, and testing. Behavioral procedures were conducted as previously described (Schafe et al., 1999). Briefly, rats were habituated to the apparatus for a minimum of $10-15 \mathrm{~min}$ and to dummy cannula removal and replacement on the day before training. Rats were trained with a single conditioning trial consisting of a $30 \mathrm{sec}, 5 \mathrm{kHz}$, $75-80 \mathrm{~dB}$ tone that co-terminated with a $1.0 \mathrm{sec}, 1.5 \mathrm{~mA}$ shock.

Rats were infused before training with either $0.5 \mu \mathrm{l}$ of artificial CSF (ACSF) or one of five doses of muscimol in ACSF (4.4, 1.1, 0.44, 0.088, or $0.001 \mathrm{nmol} / \mathrm{side}$ in $0.5 \mu \mathrm{l})$. The highest dose was chosen because of its effectiveness in blocking multiple-trial Pavlovian fear conditioning (Muller et al., 1997), and the lowest dose was chosen because of its previously documented effectiveness in the modulation of inhibitory avoidance learning (Brioni et al., 1989). The inf usion occurred an average of $49 \mathrm{~min}$ before training. For post-training inf usion groups, 4.4, 0.44 , or $0.001 \mathrm{nmol} / \mathrm{side}$ in $0.5 \mu \mathrm{l}$ of ACSF or an equivalent volume of ACSF was inf used immediately after the tone-shock pairing. The average infusion took a little less than 4 min from the offset of the US until all of the drug had been infused.

Rats were tested $24 \mathrm{hr}$ later with three $30 \mathrm{sec}$ tones $(5 \mathrm{kHz}, 75 \mathrm{~dB}$; intertrial interval, $100 \mathrm{sec}$ ) and videotaped for later scoring. To measure baseline freezing to the tone testing chamber, the $30 \mathrm{sec}$ period preceding the first tone was scored, as well as seconds freezing during each $30 \mathrm{sec}$ tone. Data were analyzed with ANOVA and Scheffe's post hoc $t$ tests. Differences were considered significant if $p<0.05$.

Extinction testing. Rats from the four groups with post-training infusions were presented with three $30 \mathrm{sec}, 5 \mathrm{kHz}, 75 \mathrm{~dB}$ tones every $24 \mathrm{hr}$ until extinction criteria had been met. The extinction criteria, adapted from previously published protocols (Morgan et al., 1993), required rats to freeze for $<5 \mathrm{sec}$ during each of the three test tones for two consecutive days.

Contextual fear conditioning and testing. Habituation and training followed the protocol for auditory fear conditioning, except the US was raised to $2 \mathrm{~mA}$ to produce robust contextual learning. Training was followed by infusion of either $0.5 \mu \mathrm{l}$ of $4.4 \mathrm{nmol}$ of muscimol/side or ACSF. At testing, rats were returned to the conditioning chamber, allowed to acclimate for 5 $\mathrm{min}$, and then observed and scored for freezing three times for $30 \mathrm{sec}$ each, with $30 \mathrm{sec}$ intervals between each scoring block. After $\sim 10 \mathrm{~min}$ in the training chamber, rats were transferred to the testing chambers for auditory tone testing as described above.

Inhibitory avoidance training and testing. Procedures for inhibitory avoidance training were based on previously published work (Brioni et al. 1989). Rats were placed in the lighted chamber facing the partition. When the rat turned to face the back wall of the chamber, the door to the dark chamber was opened, and latency to enter was recorded. When rats completely entered the dark chamber (all four feet on the floor), they received a shock $(0.45$ or $2 \mathrm{~mA}, 1 \mathrm{sec})$, followed immediately by inf usion of muscimol (4.4, 0.44, or $0.001 \mathrm{nmol} / \mathrm{side}$ in $0.5 \mu \mathrm{l}$ of ACSF) or an equivalent volume of ACSF. Rats were tested after $48 \mathrm{hr}$ in the same manner as training, but without receiving a shock. Testing was terminated either when the rat entered the dark chamber or after $600 \mathrm{sec}$ without entry. Multiple groups were statistically analyzed with the nonparametric Kruskal-Wallis ANOVA (because of the inequality of the SDs and termination of testing after $600 \mathrm{sec}$ ), whereas individual pairs were analyzed using Mann-Whitney $U$ tests.

Rats trained with the $2 \mathrm{~mA}$ shock were videotaped during testing to measure freezing to the inhibitory avoidance apparatus. Rats were placed in the light chamber, allowed $10 \mathrm{sec}$ to acclimate to the context, and then recorded for $2.5 \mathrm{~min}$. Freezing data were collected for three $30 \mathrm{sec}$ periods, separated by $30 \mathrm{sec}$ intervals. After the freezing trials, the inhibitory avoidance testing began when the rats turned to face away from the door and continued as described above.

After inhibitory avoidance testing, the 4.4 and $0.001 \mathrm{nmol}$ muscimol and the ACSF groups that received the $0.45 \mathrm{~mA}$ shock were trained in the auditory fear conditioning paradigm. Rats in the $4.4 \mathrm{nmol}$ of muscimol/side and ACSF groups received post-training infusions of $4.4 \mathrm{nmol}$ of musci$\mathrm{mol} / \mathrm{side}$ and $0.5 \mu \mathrm{l}$ of ACSF, respectively, and the remaining rats received pre-training infusions of $4.4 \mathrm{nmol}$ of muscimol/side.
Histology. To verify infusion cannula tip locations, rats were anesthetized with an overdose of chloral hydrate $(600 \mathrm{mg} / \mathrm{kg}, \mathrm{i} . \mathrm{p}$.$) and perfused$ transcardially with $10 \%$ buffered formalin. The brains were post-fixed in $30 \%$ sucrose in formalin and subsequently blocked, sectioned on a cryostat at 50-60 $\mu \mathrm{m}$, and stained for Nissl using either $0.5 \%$ cresyl violet or $0.25 \%$ thionine. Sections were coverslipped with Permount and examined under light microscopy for tip penetration into the amygdala.

\section{RESULTS}

\section{Pre-training functional inactivation of the amygdala dose-dependently impairs acquisition of auditory fear conditioning}

Previous studies in our laboratory have shown that pre-training functional inactivation of LBA with high doses of muscimol disrupts acquisition of auditory and contextual fear conditioning (Muller et al., 1997). We have recently extended these findings to show that immediate post-training infusions of muscimol have no effect on the consolidation of auditory fear conditioning (Wilensky et al., 1999). However, the results of these studies cannot be compared directly with those of inhibitory avoidance experiments, because they used multiple-trial conditioning instead of single-trial learning, which may have allowed excessive time during training and before drug infusion for memory consolidation. Furthermore, the previous studies used doses of muscimol much higher than those typically used in studies of inhibitory avoidance (Brioni et al., 1989). Therefore, the first experiment of the present study examined the effects of pre-training administration of different doses of muscimol on single-trial auditory fear conditioning. Rats were inf used with either vehicle (ACSF) or one of five doses of muscimol $(0.001,0.088,0.44,1.1$, and $4.4 \mathrm{nmol})$ before auditory fear conditioning and assessed for fear retention the following day (Fig. $1 A$ ).

Figure $1 B$ shows the infusion cannula tip locations. These were mostly located in the LA, with a few just outside of the LBA. All cannulas $<0.5 \mathrm{~mm}$ outside of the LBA were included in the analysis (Martin, 1991). One animal (results not shown) was excluded from analysis for incorrect placement.

Figure $1 C$ shows the mean \pm SE percent freezing averaged across all tones, whereas Figure $1 D$ shows the results for each of the three trials. Baseline freezing scores for the $30 \mathrm{sec}$ period before CS onset did not differ among groups $\left[F_{(5,31)}=1.11 ; p>\right.$ 0.05]. The mean \pm SE percent baseline freezing for all animals infused before training was $4 \pm 0.77 \%$, indicating that fear did not generalize from the conditioning chamber to the testing chamber. In contrast, the ANOVA for freezing scores during CS presentation showed a significant effect of drug concentration $\left[F_{(5,31)}=\right.$ $8.38 ; p<0.001]$, with nonsignificant effects for trial $\left[F_{(2,62)}=1.60\right]$ and drug-by-trial interaction $\left[F_{(10,64)}=0.50\right]$. Consistent with previous work in our laboratory (Muller et al., 1997; Wilensky et al., 1999), infusion of high doses of muscimol before conditioning (4.4 or $1.1 \mathrm{nmol}$ ) resulted in significant memory impairments relative to both ACSF-infused controls $(p<0.01$, Scheffe's test $)$ and the lowest dose $(0.001 \mathrm{nmol}, p<0.05)$. Infusion of $0.44 \mathrm{nmol}$ also resulted in a significant impairment relative to ACSF-infused controls $(p<0.05)$. However, groups given the lowest doses $(0.088$ and $0.001 \mathrm{nmol}$ ) did not differ from ACSF controls. These results show a clear relationship between the dose of muscimol received and the degree of disruption of auditory tone conditioning.

\section{Post-training functional inactivation of the amygdala does not impair auditory fear conditioning}

We next evaluated whether post-training functional inactivation of LBA with muscimol would affect single-trial auditory fear conditioning similarly to inhibitory avoidance learning (Brioni et al., 1989; Izquierdo et al., 1997; Z anatta et al., 1997). Rats were trained as before with one-trial auditory conditioning and given immediate post-training infusion of either ACSF or one of three doses of muscimol used in the first experiment $(4.4,0.44$, or $0.001 \mathrm{nmol}$ ), including the dose $(4.4 \mathrm{nmol})$ that clearly disrupted conditioning in 

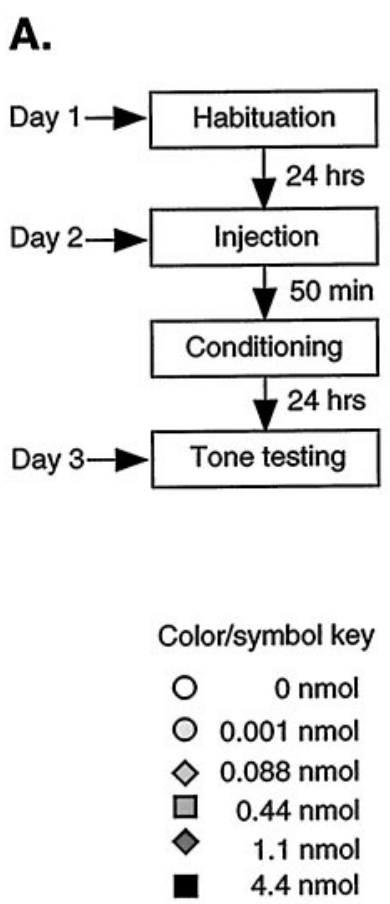

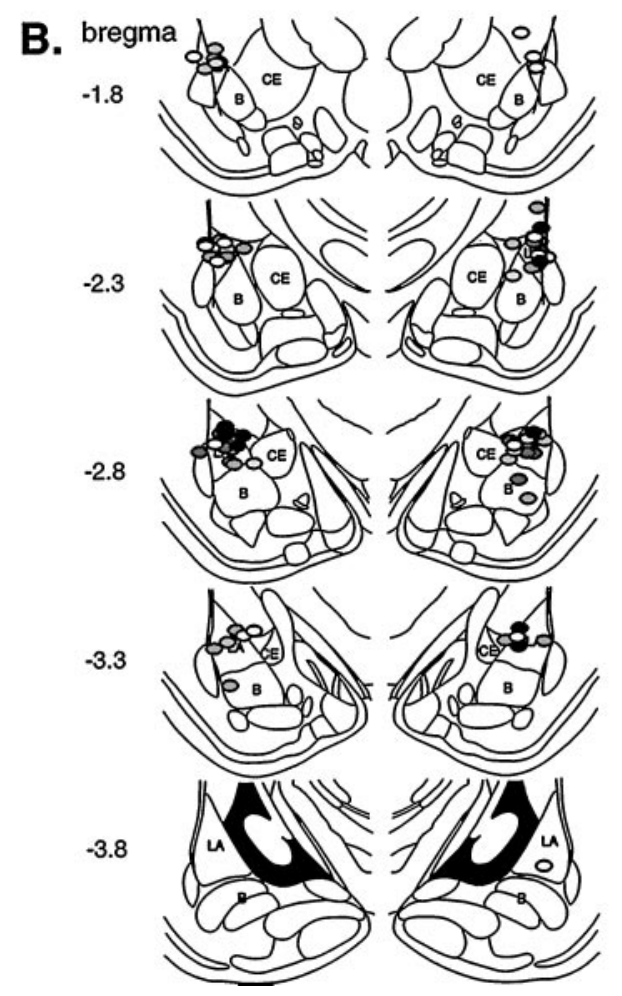

C.

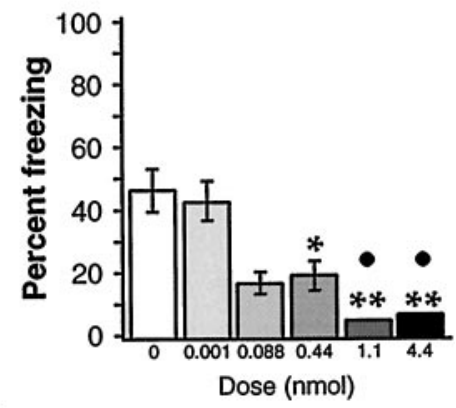

D.

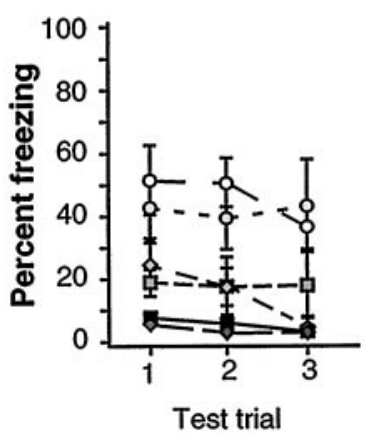

Figure 1. Auditory Pavlovian fear conditioning: pre-training infusions. $A$, Outline of general procedures. $B$, Cannula tip placement for all animals included in the analysis (drawings adapted from Paxinos and Watson, 1997). Numbers on the left indicate millimeters posterior to bregma. $L A$, Lateral nucleus; $B$, basal nucleus; $C E$, central nucleus. $C$, Mean \pm SE percent freezing during tone tests per group averaged across all tone trials. Groups with increasing doses show a decrease in freezing levels, with the highest two doses $(n=5$ each) significantly different from both vehicle $(n=9$; $* * p<0.01)$ and the lowest muscimol dose $(n=5 ; p<0.05)$. The intermediate dose $(0.44 \mathrm{nmol}, n=8)$ also significantly differed from vehicle (* $p<0.05)$, whereas the lowest two doses $(0.088 \mathrm{nmol}, n=5 ; 0.001 \mathrm{nmol}, n=5)$ did not. $D$, Mean \pm SE percent freezing per group during each tone trial. All three trials show the same pattern of significance described in $C$.

the first experiment and the dose $(0.001 \mathrm{nmol})$ that has been shown to impair inhibitory avoidance when inf used after training (Brioni et al., 1989). The following day, rats were tested for retention of fear conditioning (Fig. 2A).

Cannula tip placements were similar to those of the first experiment (Fig. 2B). One animal was excluded from the analysis because of cannula placement in the ventricles.

Figure $2 C$ shows the mean $\pm \mathrm{SE}$ percent freezing averaged across all tones, whereas Figure $2 D$ shows the results for each of the three trials. Freezing scores for the $30 \mathrm{sec}$ period before CS onset did not differ between groups $\left[F_{(3,38)}=0.38 ; p>0.05\right]$. For freezing scores during the CS, the ANOVA showed a significant effect for trials $\left[F_{(2,76)}=3.37 ; p<0.05\right]$, in which trials 1 and 3 were significantly different $(p<0.05)$. However, no significant effect of $\operatorname{drug}\left[F_{(3,38)}=0.12\right]$ or drug-by-trial interaction $\left[F_{(6,76)}=0.92\right]$ was observed. Thus, in contrast to the dose-dependent effect of muscimol on fear retention after pre-training inf usions, groups receiving inf usions of muscimol immediately after auditory fear conditioning did not differ from controls at any dose.

Another measure of the strength of conditioning is the rate at which the conditioned response extinguishes. If post-training intraamygdala infusions of muscimol attenuated fear consolidation in a manner not observable after $24 \mathrm{hr}$, then one would expect muscimol-treated rats to extinguish more quickly than controls. To evaluate this possibility, rats from each post-training infusion group were tested for rate of extinction. The ANOVA revealed that groups did not differ significantly in the average number of days to reach extinction criterion $\left[F_{(3,19)}=0.43\right.$; Fig. $\left.2 E\right]$. Thus, although pre-training inactivation disrupts learning, post-training inactivation of the amygdala appears to have no effect on Pavlovian fear conditioning, measured both by freezing in the first three tone trials and by days required to reach extinction.

\section{Post-training functional inactivation of the amygdala does not impair contextual fear conditioning}

In the previous two experiments, we evaluated the impact of preor post-training functional inactivation of LBA on auditory fear conditioning and found that, unlike in the inhibitory avoidance literature, post-training infusions did not affect the learning. In the third experiment, we evaluated the effects of post-training amygdala inactivation on contextual fear conditioning. Contextual Pavlovian conditioning may parallel inhibitory avoidance learning more closely than auditory Pavlovian conditioning because of the associations with the context in each paradigm. This comparison is particularly relevant in light of a recent report (Vazdarjanova and McGaugh, 1999) that suggests that the strength of contextual fear conditioning can be modulated by post-training administration of lidocaine into the amygdala, similarly to inhibitory avoidance. To determine whether the role of the amygdala differs in auditory and contextual conditioned fear, we infused the high dose of muscimol used in the previous experiments $(4.4 \mathrm{nmol})$ into the LBA of rats after one-trial Pavlovian fear conditioning and then assessed retention of both contextual and auditory fear in each rat (Fig. $3 A$ ).

Figure $3 B$ shows representative inf usion cannula tip locations for all rats. Tips were located in or just outside of the LA.

Figure $3 C$ shows the mean $\pm \mathrm{SE}$ percent freezing averaged across all auditory trials, whereas Figure $3 D$ shows the results for each individual tone. Overall freezing is higher than in experiment 2, presumably because of the higher US intensity. Consistent with the results of the second experiment, the ANOVA showed a significant effect for trial $\left[F_{(2,42)}=4.54 ; p<0.05\right]$ between trials 1 and $3(p<0.05)$. However, no significant effect of drug $\left[F_{(1,21)}=\right.$ $0.06]$ or drug-by-trial interaction $\left[F_{(2,42)}=1.19\right]$ was observed.

Figure $3 E$ shows the mean $\pm \mathrm{SE}$ percent freezing averaged across all three context test periods, whereas Figure $3 F$ shows the 

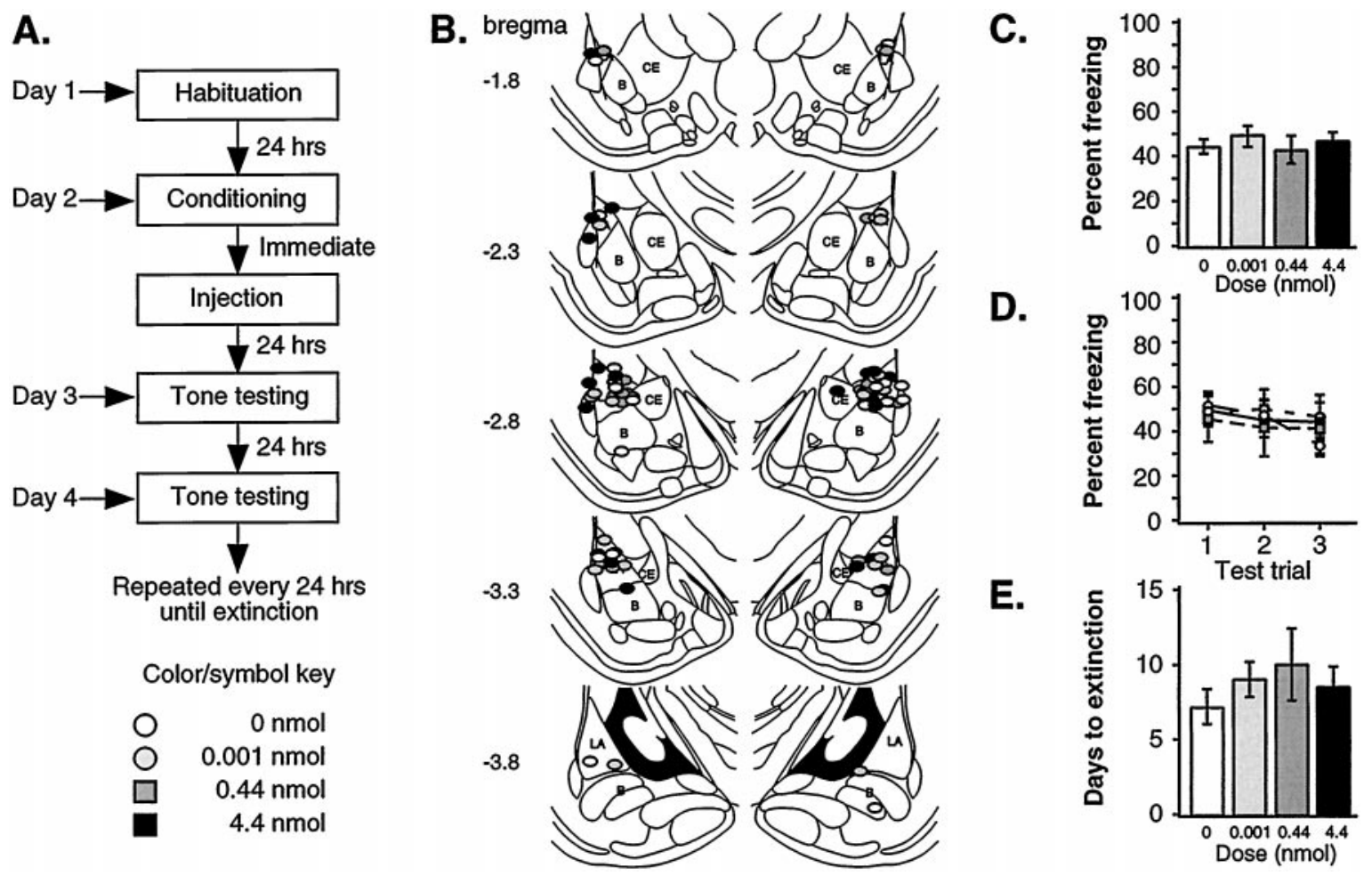

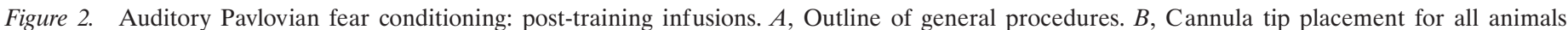

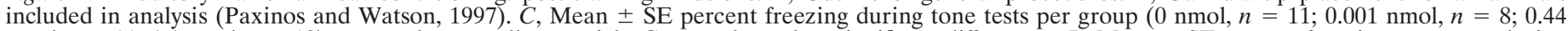

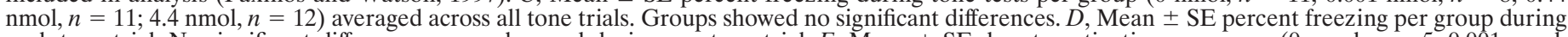

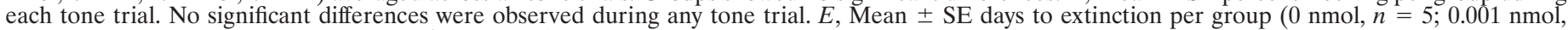
$n=5 ; 0.44 \mathrm{nmol}, n=7 ; 4.4 \mathrm{nmol}, n=6$ ). No significant differences were observed.

results for each individual period. As with auditory conditioning, the ANOVA detected no significant effects for group $\left[F_{(1,21)}=\right.$ $0.86]$, trial $\left[F_{(2,42)}=0.52\right]$, or group-by-trial $\left[F_{(2,42)}=0.27\right]$. Thus, in contrast to the finding of Vazdarjanova and McGaugh (1999), in which inactivation of the LBA with lidocaine affected another type of contextual conditioning task, the present findings indicate that post-training LBA inactivation with muscimol has no effect on contextual Pavlovian fear conditioning.

\section{Post-training functional inactivation of the amygdala impairs inhibitory avoidance learning but not Pavlovian fear conditioning}

The results of the previous three experiments indicate that neural activity in the amygdala during but not immediately after training is required for acquisition of Pavlovian fear conditioning. In contrast, numerous studies have reported effects of post-training infusions of GABAergic drugs, including muscimol, on memory consolidation of inhibitory avoidance learning (Brioni et al., 1989; Castellano et al., 1989; Dickinson-Anson and McGaugh, 1997; Izquierdo et al., 1997). To determine whether we could find similar effects, we trained rats using a single-trial inhibitory avoidance learning task (Brioni et al., 1989). Given that our Pavlovian conditioning paradigm produced $\sim 50 \%$ freezing in controls, we chose from the literature and from pilot data (data not shown) parameters that resulted in $\sim 50 \%$ retention in our inhibitory avoidance task. Immediately after training, rats were infused with either ACSF or one of the three doses of muscimol used in the second experiment $(4.4,0.44$, or $0.001 \mathrm{nmol})$. Rats were tested for retention of inhibitory avoidance learning $48 \mathrm{hr}$ after training (Fig. 4A).

Figure $4 B$ shows the infusion cannula tip locations, and again, tips were mostly located in the LA. Two animals were excluded from the analysis, one for cannula tip location in the ventricles and the other for an indeterminate cannula placement.

Figure 4, $C$ and $D$, respectively, shows the mean \pm SE latency to enter the dark chamber during training and for the difference between training and testing. The Kruskal-Wallis ANOVA on the difference scores showed a significant effect of group $[H(\mathrm{df}=3$; $n=47)=9.76 ; p<0.05$ ] with a significant difference between the highest dose group and vehicle controls $(p<0.01)$ and between the highest dose group and the lowest dose group $(p<0.05)$. Consistent with previous work (Brioni et al., 1989; Izquierdo et al., 1997; Zanatta et al., 1997), post-training inactivation of the amygdala with muscimol dose-dependently impaired inhibitory avoidance learning. However, unlike the results of Brioni et al. (1989), who found effects only at low doses, our results are more consistent with other inhibitory avoidance studies in the literature that found effects using our higher dose (Izquierdo et al., 1997; Zanatta et al., 1997).

We next used rats that had been trained in the inhibitory avoidance task and retrained them in the auditory fear conditioning paradigm. One group of rats received muscimol $(4.4 \mathrm{nmol})$ before training. The other two groups received an immediate posttraining infusion of either ACSF or muscimol (4.4 nmol; Fig. $4 A$ ). In this manner, we were able to evaluate the impact of post-training functional inactivation of the amygdala on the two single-trial learning paradigms in the same animals with the same cannula placements.

Figure $4 E$ displays freezing scores averaged across all tone trials, whereas Figure $4 F$ shows the data for each of the three tone trials. Freezing scores for retrained rats were somewhat lower than those for naive animals, which was expected because of previous exposure to the aversive US. The ANOVA showed a significant effect of drug $\left[F_{(2,32)}=8.15 ; p<0.01\right]$, with which the pre-inf used group differed significantly from both post-infused groups $(p<0.05$; Scheffe's test), a significant effect for trial $\left[F_{(2,64)}=5.75 ; p<0.01\right]$ between trials 1 and $2(p<0.05)$ and between trials 1 and $3(p<$ $0.05)$, and no significant effect for group-by-trial $\left[F_{(12,64)}=0.97\right]$. Pre-training infusions of muscimol impaired fear conditioning, whereas rats infused after training did not differ from ACSFinfused controls $(p>0.05)$. Thus, consistent with our previous experiments, pre-training administration of muscimol into the 


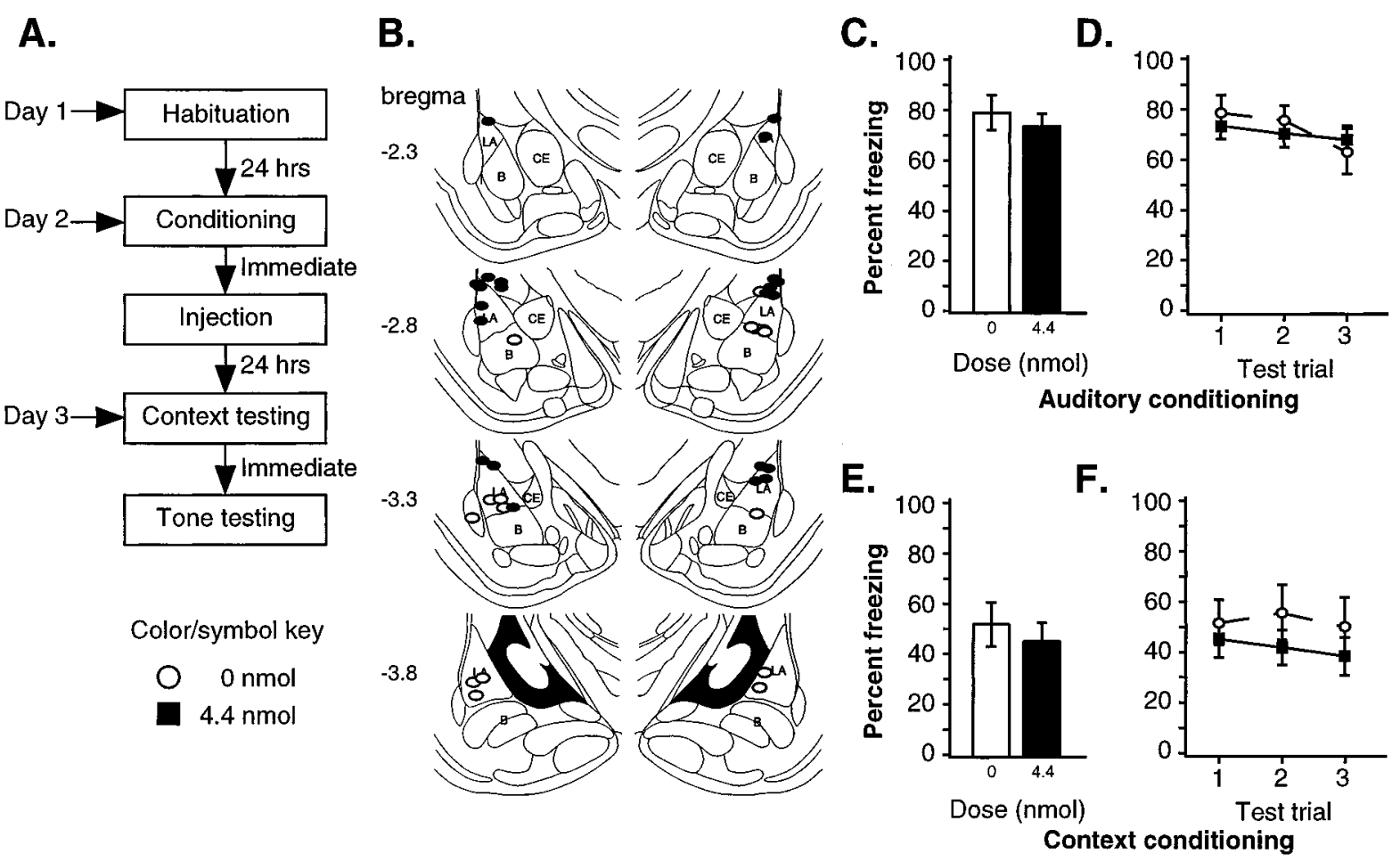

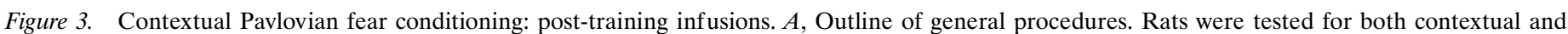

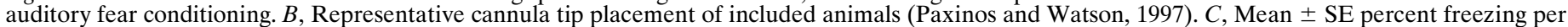

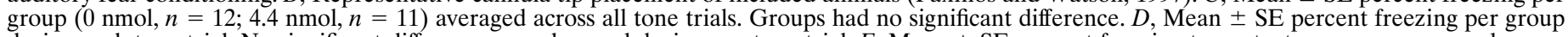

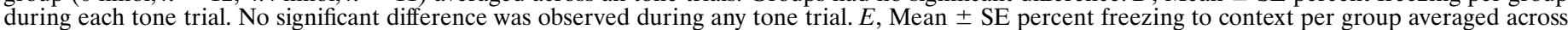

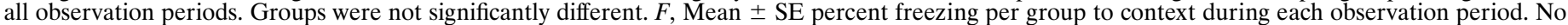
significant differences were observed between groups during any observation period.

LBA impaired fear acquisition, whereas, in contrast to inhibitory avoidance, post-training infusions did not affect retention of auditory fear conditioning.

Because we tested our rats at $48 \mathrm{hr}$ in the inhibitory avoidance experiment and at $24 \mathrm{hr}$ in the Pavlovian fear conditioning experiments, it may be argued that this difference is responsible for the different effects observed in the two paradigms. If true, then we would expect to observe impaired retention after $48 \mathrm{hr}$ in rats given immediate post-training infusions of muscimol after Pavlovian conditioning. We therefore analyzed data at $48 \mathrm{hr}$ from rats given extinction training in our second experiment (discussed above). The ANOVA showed no significant effects for drug $\left[F_{(3,19)}=2.11\right]$, trial $\left[F_{(2,38)}=2.12\right]$, or drug-by-trial interaction $\left[F_{(6,38)}=0.41\right]$. These results are identical to those found at $24 \mathrm{hr}$ after training and fail to support the hypothesis that time of testing significantly affects the results of post-training GABAergic manipulations of the amygdala.

Finally, we addressed the question of whether the differences obtained using Pavlovian fear conditioning and inhibitory avoidance learning paradigms might be attributable to differences in foot shock intensity. For example, evidence suggests that parameters such as foot shock intensity can affect the ability of amnesic agents to interfere with memory, presumably by influencing the rate of memory consolidation (Ray and Bivens, 1968). Thus, it may be argued that our ability to modulate inhibitory avoidance learning but not Pavlovian fear conditioning was attributable to a lower shock intensity in the former $(0.45 \mathrm{~mA})$. Therefore, we repeated our inhibitory avoidance experiment using a $2 \mathrm{~mA}, 1 \mathrm{sec}$ foot shock, the highest shock intensity used in our Pavlovian fear experiments. As in previous experiments, rats were infused immediately after training, with either ACSF or $4.4 \mathrm{nmol}$ of muscimol/ side, and were tested for retention $48 \mathrm{hr}$ later (Fig. $5 \mathrm{~A}$ ). To assay for possible Pavlovian conditioning to the inhibitory avoidance chamber, which may have confounded our inhibitory avoidance measures, we also scored the rats for three $30 \mathrm{sec}$ periods for freezing to context.
Figure $5 B$ shows the infusion cannula tip locations, and again, tips were mostly located in the LA. One animal was excluded from the analysis because of damage throughout the LA.

Figure $5 C$ shows the mean $\pm \mathrm{SE}$ percent freezing averaged across all three context test periods, whereas Figure $5 D$ shows the results for each individual test period. Freezing during the test periods was very low (averages were $<10 \%$ ), and the ANOVA detected no significant effects for group $\left[F_{(1,13)}=1.23\right]$, trial $\left[F_{(2,26)}\right.$ $=2.24]$, or group-by-trial interaction $\left[F_{(2,26)}=2.15\right]$. Therefore, any differences in avoidance latencies between muscimol-treated and vehicle groups cannot be attributed to differences in freezing.

Figure $5, E$ and $F$, shows the mean \pm SE latency to enter the dark chamber during training and the difference between training and testing. Mann-Whitney $U$ tests showed a significant effect of group on the difference scores (adjusted $Z=-2.8 ; p<0.01$ ). Thus, even when shock intensity and duration were matched to those used in our Pavlovian fear conditioning experiments, we found a strong modulatory effect on inhibitory avoidance learning with posttraining functional inactivation of the amygdala. Collectively, the results of all of our experiments strongly favor the hypothesis that fundamental differences exist with respect to the involvement of the amygdala in memory consolidation of Pavlovian fear conditioning and inhibitory avoidance learning.

\section{DISCUSSION}

Although a considerable amount of progress has been made in understanding the neural basis of fear conditioning, the exact role of the amygdala still remains controversial (Cahill et al., 1999; Fanselow and LeDoux, 1999). Results of studies using Pavlovian fear conditioning paradigms have suggested that essential aspects of fear learning take place in the amygdala, whereas studies based on inhibitory avoidance learning argue that the amygdala modulates the consolidation of fear memories in other brain areas. Because lesions of the amygdala generally abolish the expression of conditioned freezing (but see Maren, 1999), proponents of this latter view have argued that unambiguous conclusions cannot be 

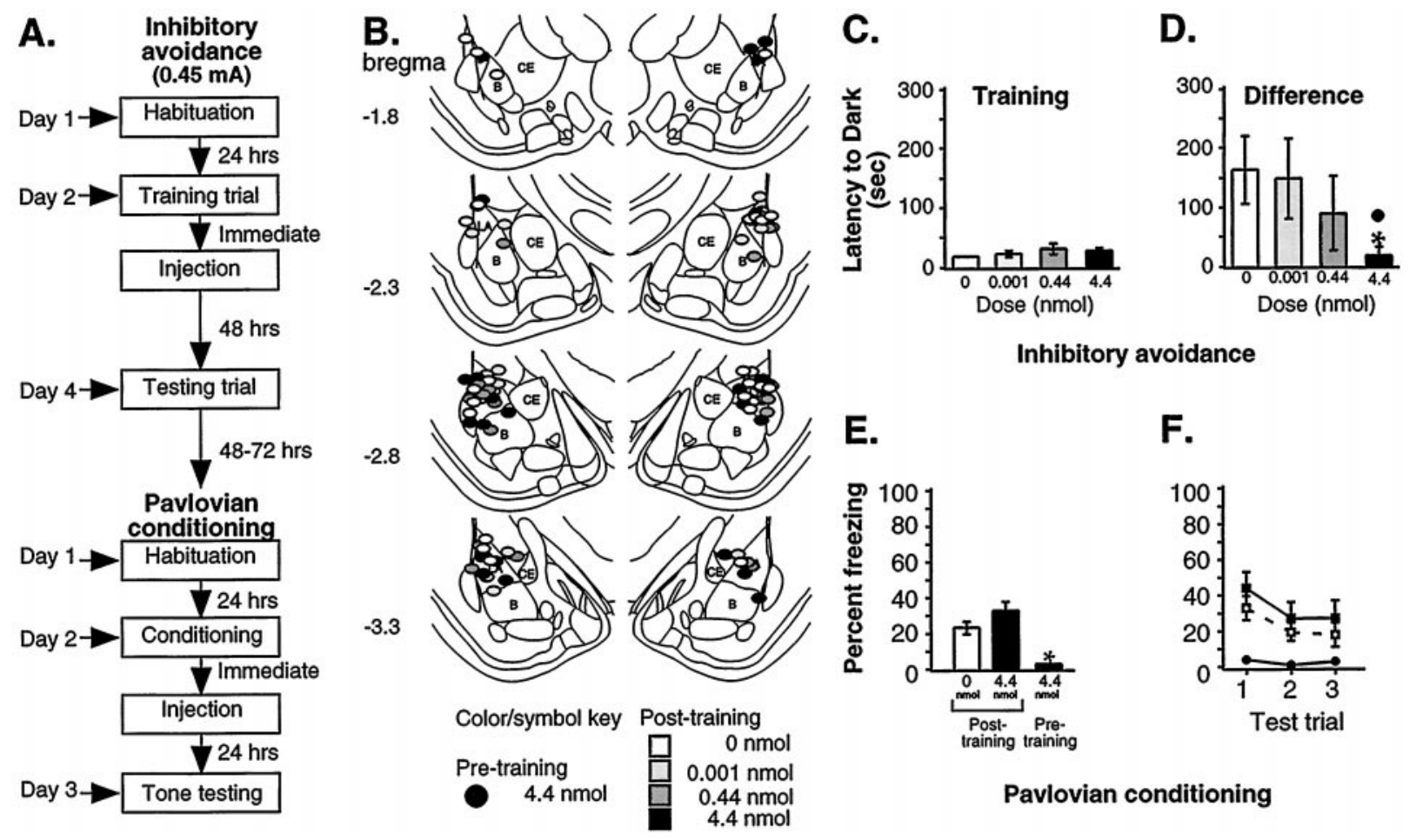

Pavlovian conditioning

Figure 4. Inhibitory avoidance learning: post-training infusions, $0.45 \mathrm{~mA}$ shock. $A$, Outline of general procedures. Inhibitory avoidance learning was followed by Pavlovian conditioning. $B$, Cannula tip placement for all animals included in the analysis (Paxinos and Watson, 1997). $C$, Mean \pm SE latency (seconds) to enter the dark chamber during training. Groups did not differ by dose $(0 \mathrm{nmol}, n=13 ; 0.001 \mathrm{nmol}, n=11 ; 0.44 \mathrm{nmol}, n=11 ; 4.4 \mathrm{nmol}, n=$ 12). $D$, Mean \pm SE latency (seconds) for the difference between testing and training. The highest dose of muscimol was significantly different from both vehicle $\left({ }^{*} p<0.01\right)$ and the lowest muscimol dose $\left({ }^{*}<0.05\right)$. E. Mean \pm SE percent freezing for each retrained group averaged across all tone trials. Muscimol continued to block freezing when administered before training $(n=11)$ but did not produce a significant difference between post-training groups $(0 \mathrm{nmol}, n=13 ; 4.4 \mathrm{nmol}, n=11) .{ }^{*} p<0.05$ relative to groups infused after training. $F$, Mean \pm SE percent freezing per group during each tone trial. No significant differences between post-training groups were observed during any tone trial.

drawn about the role of the amygdala in fear memory consolidation using permanent lesions (Cahill et al., 1999). Furthermore, because pharmacological manipulations of the amygdala immediately after training modulate the strength of inhibitory avoidance learning (McGaugh et al., 1995; Cahill and McGaugh, 1998; Packard and Teather, 1998), it has been argued that learning impairments observed in studies using pre-training infusions of drugs such as muscimol and AP-5 do not necessarily indicate that the amygdala is the site of plasticity underlying fear learning (McGaugh et al., 1995).

One possible resolution of this controversy is that both views are correct; namely, that in Pavlovian fear conditioning the amygdala serves as the site of plasticity underlying fear learning, whereas in inhibitory avoidance learning the amygdala serves to modulate the strength of aversive memory elsewhere. The experiments in the present paper were designed to test this possibility by directly comparing post-training pharmacological manipulations of the amygdala in both paradigms. Although pre-training functional inactivation of the LBA with muscimol dose-dependently impaired Pavlovian fear conditioning, immediate post-training inactivation had no effect. In contrast, post-training inactivation of the LBA consistently impaired inhibitory avoidance learning. These results are consistent with those of previous studies in which intraamygdala administration of AP-5 impaired Pavlovian fear conditioning if given before, but not immediately after, training (Maren et al., 1996b). In contrast, post-training infusion of AP-5 has been shown to impair inhibitory avoidance learning (Liang et al., 1994). Collectively, the findings indicate that Pavlovian fear conditioning and inhibitory avoidance are differentially affected by post-training pharmacological manipulations of the amygdala and suggest that fundamental differences exist in the underlying neural mechanisms mediating memory consolidation in the two learning paradigms.

Procedural differences exist between Pavlovian fear conditioning and inhibitory avoidance learning that may account for the differ- ent role of the amygdala in each paradigm. In the former, the animal is presented with tones (CS) and shocks (US) independent of its behavior. However, inhibitory avoidance learning is an example of instrumental learning, in which shock delivery is contingent on the animal's response. It is thus likely that the ability to affect one kind of learning and not the other with post-training manipulations of the amygdala reflects differences in the relative complexity of the neural network underlying each type of learning. Indeed, a number of lesion studies have implicated the entorhinal and parietal cortex in late memory phases of inhibitory avoidance learning (Izquierdo et al., 1997; Zanatta et al., 1997), whereas, for example, Pavlovian fear conditioning is spared after entorhinal cortex lesions (Phillips and LeDoux, 1995). Furthermore, although lesion studies have consistently implicated the amygdala in Pavlovian fear conditioning (LeDoux et al., 1990; Maren et al., 1996a; Maren, 1998), lesions of the amygdala appear to have less clear-cut effects on inhibitory avoidance learning, especially if given after training (Liang et al., 1982; Parent et al., 1995). Although this latter finding has been used as evidence in favor of the view that the amygdala is not the site of memory consolidation of conditioned fear, it is equally consistent with the notion that the amygdala plays a fundamentally different role in Pavlovian fear conditioning and inhibitory avoidance learning.

In experiment 3, we found that post-training functional inactivation of the LBA did not affect contextual Pavlovian fear conditioning. This finding stands in contrast to one recent report (Vazdarjanova and McGaugh, 1999) (also see Sacchetti et al., 1999), which demonstrated impairments in retention of contextual Pavlovian fear conditioning after post-training inactivation of the LBA. In that study, rats receiving the anesthetic lidocaine after exposure to multiple shocks in a closed arm of a Y maze spent less time freezing when reexposed to a nonshock arm of the Y maze and were more likely to enter the shock arm of the maze. The requirements of this task distinguish it from a simple context CS 

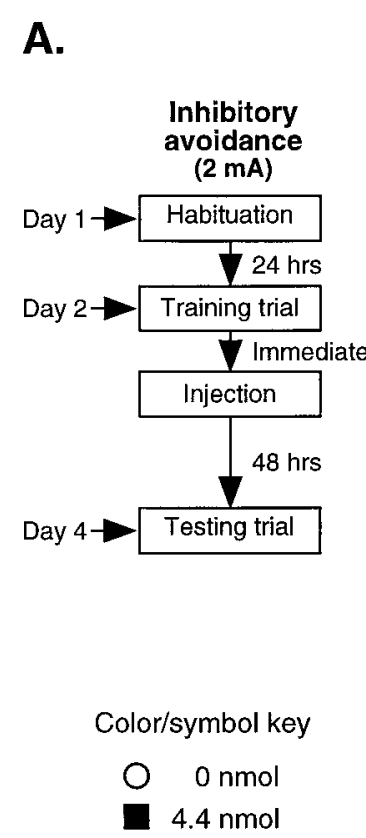

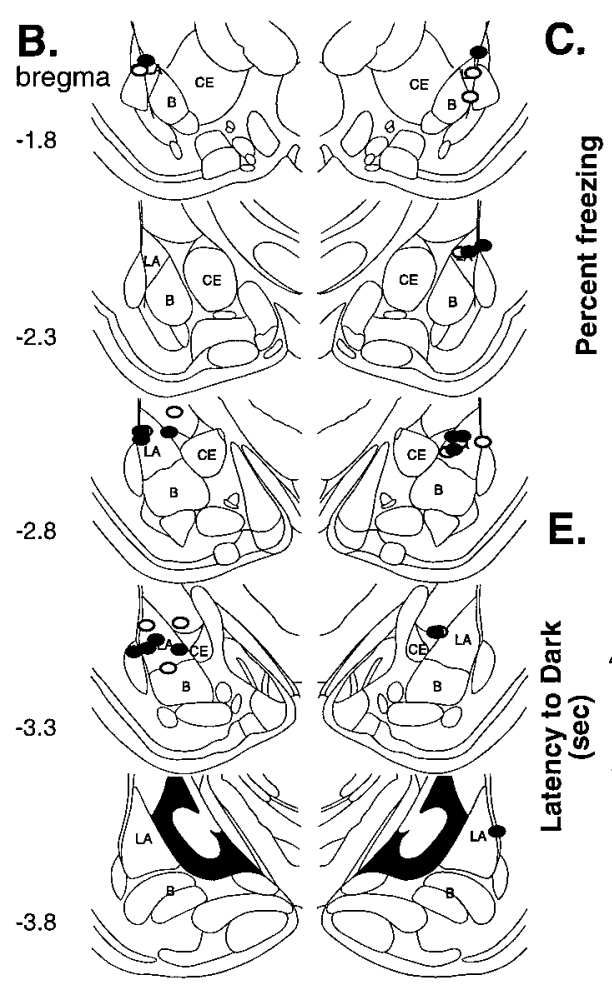

D.

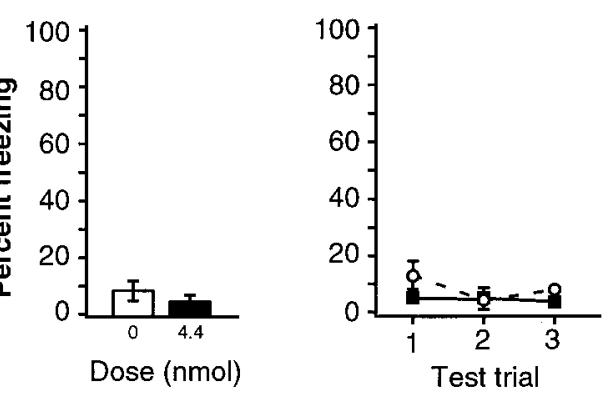

Freezing to light chamber

$\mathbf{F}$.

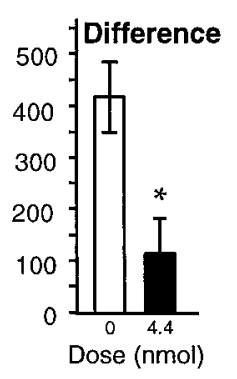

Inhibitory avoidance

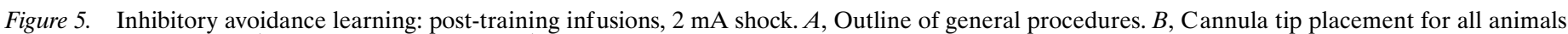

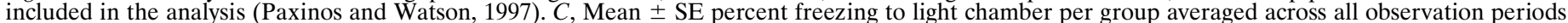

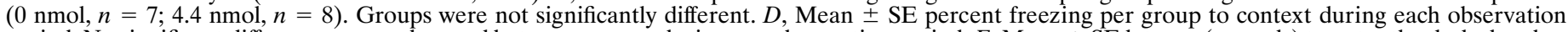

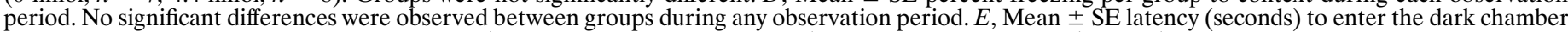

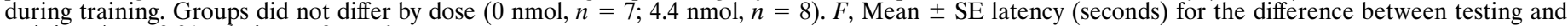
training. ${ }^{*} p<0.01$ relative to 0 nmol group.

exposure by placing the rat in a nonshock arm, rather than the arm associated with shock at the time of training. This different type of exposure during testing, and the various behavioral choices available to the rat, may account in part for the different findings between our study and that of Vazdarjanova and McGaugh (1999). However, although such procedural details in testing may partially account for the different findings, it is our hypothesis that fundamental differences in training, rather than testing, are the main sources of the differences between the Pavlovian conditioning and inhibitory avoidance learning. Thus, we believe that different testing methods may not adequately account for the differential effects on contextual fear in the two studies.

Another, potentially more substantive, difference between the two sets of experiments lies in the drugs used to inactivate the amygdala. Although both muscimol and lidocaine reversibly inactivate the amygdala, muscimol agonizes the ionotropic $\mathrm{GABA}_{\mathrm{A}}$ receptor to inhibit neural transmission, whereas lidocaine is believed to inhibit transmission by inactivating $\mathrm{Na}^{+}$channels using the cAMP signaling pathway (Onozuka et al., 1993). Lidocaine has been shown to inhibit intracellular cAMP production, possibly through an interaction with a $G_{i}$ regulatory subunit of adenylate cyclase (Roux et al., 1989), and also to suppress the activity of the cAMP-dependent protein kinase (PKA) (Onozuka et al., 1993). The cAMP cascade and PKA have been implicated in the molecular events underlying memory consolidation in a wide variety of species, including fear conditioning in rodents (Alberini et al., 1995; Bourtchouladze et al., 1998; Schafe et al., 1999). Furthermore, recent work in our laboratory has indicated that immediate post-training disruption of PKA activity in the LBA impairs consolidation of Pavlovian conditioning (Schafe and LeDoux, 2000). As a result, the effects found on context memory after post-training inf usions of lidocaine (Vazdarjanova and McGaugh, 1999), along with our data, might alternatively suggest the opposite conclusion; namely, that synaptic activity in the LBA is required during learning, but afterward consolidation in the amygdala proceeds inde- pendently of synaptic activity and is instead dependent on intracellular signaling.

The results of the present study clearly indicate that amygdala inactivation differentially affects inhibitory avoidance and Pavlovian conditioning and that pre-training, but not post-training, functional inactivation of the LBA impairs acquisition of Pavlovian fear conditioning to both contextual and auditory stimuli (Muller et al., 1997; Wilensky et al., 1999). This dual role of the amygdala in Pavlovian fear conditioning and inhibitory avoidance learning suggests a wider role for LBA in fear learning and memory than may have been previously acknowledged. Future work should carefully consider procedural differences in the behavioral paradigms used to study fear learning and how these differences, however subtle, can influence the neurobiology of fear.

\section{REFERENCES}

Alberini CM, Ghirardi M, Huang Y, Nguyen PV, Kandel ER (1995) A molecular switch for the consolidation of long-term memory: cAMPinducible gene expression. Ann NY Acad Sci 758:261-286.

Bourtchouladze R, Abel T, Berman N, Gordon R, Lapidus K, Kandel ER (1998) Different training procedures recruit either one or two critical periods for contextual memory consolidation, each of which requires protein synthesis and PKA. Learn Mem 5:365-374.

Brioni JD, Nagahara AH, McGaugh JL (1989) Involvement of the amygdala GABAergic system in the modulation of memory storage. Brain Res 487:105-112.

Cahill L, McGaugh JL (1998) Mechanisms of emotional arousal and lasting declarative memory. Trends Neurosci 21:294-299.

Cahill L, Weinberger NM, Roozendaal B, McGaugh JL (1999) Is the amygdala a locus of "conditioned fear"? Some questions and caveats Neuron 23:227-228.

Castellano C, McGaugh JL (1990) Effects of post-training bicuculline and muscimol on retention: lack of state dependency. Behav Neural Biol $54: 156-164$

Castellano C, Brioni JD, Nagahara AH, McGaugh JL (1989) Post-training systemic and intra-amygdala administration of the GABA-B agonist baclofen impairs retention. Behav Neural Biol 52:170-179.

Dickinson-Anson H, McGaugh JL (1997) Bicuculline administered into 
the amygdala after training blocks benzodiazepine-induced amnesia Brain Res 752:197-202.

Dickinson-Anson H, Mesches MH, Coleman K, McGaugh JL (1993) Bicuculline administered into the amygdala blocks benzodiazepineinduced amnesia. Behav Neural Biol 60:1-4.

Fanselow MS, LeDoux JE (1999) Why we think plasticity underlying Pavlovian fear conditioning occurs in the basolateral amygdala. Neuron 23:229-232

Helmstetter FJ, Bellgowan PS (1994) Effects of muscimol applied to the basolateral amygdala on acquisition and expression of contextual fear conditioning in rats. Behav Neurosci 108:1005-1009.

Izquierdo I, Quillfeldt JA, Zanatta MS, Quevedo J, Schaeffer E, Schmitz PK, Medina JH (1997) Sequential role of hippocampus and amygdala, entorhinal cortex and parietal cortex in formation and retrieval of memory for inhibitory avoidance in rats. Eur J Neurosci 9:786-793.

LeDoux JE (2000) Emotion circuits in the brain. Annu Rev Neurosci 23:155-184.

LeDoux JE, Cicchetti P, Xagoraris A, Romanski LM (1990) The lateral amygdaloid nucleus: sensory interface of the amygdala in fear conditioning. J Neurosci 10:1062-1069.

Liang KC, McGaugh JL, Martinez Jr JL, Jensen RA, Vasquez BJ, Messing RB (1982) Post-training amygdaloid lesions impair retention of an inhibitory avoidance response. Behav Brain Res 4:237-249.

Liang KC, Hon W, Davis M (1994) Pre- and posttraining infusion of $N$-methyl-D-aspartate receptor antagonists into the amygdala impair memory in an inhibitory avoidance task. Behav Neurosci 108:241-253.

Maren S (1998) Overtraining does not mitigate contextual fear conditioning deficits produced by neurotoxic lesions of the basolateral amygdala J Neurosci 18:3088-3097.

Maren S (1999) Neurotoxic basolateral amygdala lesions impair learning and memory but not the performance of conditional fear in rats. J Neurosci 19:8696-8703.

Maren S, Fanselow MS (1996) The amygdala and fear conditioning: has the nut been cracked? Neuron 16:237-240.

Maren S, Aharonov G, Fanselow MS (1996a) Retrograde abolition of conditional fear after excitotoxic lesions in the basolateral amygdala of rats: absence of a temporal gradient. Behav Neurosci 110:718-726.

Maren S, Aharonov G, Stote DL, Fanselow MS (1996b) N-Methyl-Daspartate receptors in the basolateral amygdala are required for both acquisition and expression of conditional fear in rats. Behav Neurosci 110:1365-1374.

Martin JH (1991) Autoradiographic estimation of the extent of reversible inactivation produced by microinjection of lidocaine and muscimol in the rat. Neurosci Lett 127:160-164.

McGaugh JL, Cahill L, Parent MB, Mesches MH, Coleman-Mesches K, Salinas JA (1995) Involvement of the amygdala in the regulation of memory storage. In: Plasticity in the central nervous system: learning and memory (McGaugh JL, ed), pp 17-39. Mahwah, NJ: Erlbaum.

Morgan MA, Romanski LM, LeDoux JE (1993) Extinction of emotional learning: contribution of medial prefrontal cortex. Neurosci Lett 163:109-113.

Muller J, Corodimas KP, Fridel Z, LeDoux JE (1997) Functional inactivation of the lateral and basal nuclei of the amygdala by muscimol infusion prevents fear conditioning to an explicit conditioned stimulus and to contextual stimuli. Behav Neurosci 111:683-691.
Onozuka M, Watanabe K, Imai S, Nagasaki S, Yamamoto T (1993) Lidocaine suppresses the sodium current in Euhadra neurons which is mediated by cAMP-dependent protein phosphorylation. Brain Res 628:335-339.

Packard MG, Teather LA (1998) Amygdala modulation of multiple memory systems: hippocampus and caudate-putamen. Neurobiol Learn Mem 69:163-203.

Parent MB, Quirarte GL, Cahill L, McGaugh JL (1995) Spared retention of inhibitory avoidance learning after posttraining amygdala lesions. Behav Neurosci 109:803-807.

Paxinos G, Watson C (1986) The rat brain in stereotaxic coordinates, Ed 2. San Diego: Academic.

Paxinos G, Watson C (1997) The rat brain in stereotaxic coordinates: computer graphics files, compact Ed 3. San Diego: Academic.

Phillips RG, LeDoux JE (1995) Lesions of the fornix but not the entorhinal or perirhinal cortex interfere with contextual fear conditioning. J Neurosci 15:5308-5315.

Quirk GJ, Armony JL, LeDoux JE (1997) Fear conditioning enhances different temporal components of tone-evoked spike trains in auditory cortex and lateral amygdala. Neuron 19:613-624.

Ray OS, Bivens LW (1968) Reinforcement magnitude as a determinant of performance decrement after electroconvulsive shock. Science 160:330-332.

Romanski LM, Clugnet M-C, Bordi F, LeDoux JE (1993) Somatosensory and auditory convergence in the lateral nucleus of the amygdala. Behav Neurosci 107:444-450.

Roozendaal B, Cahill L, McGaugh JL (1996) Interaction of emotionally activated neuromodulatory systems in regulating memory storage. In: Brain processes and memory (Ishikawa K, McGaugh JL, Sakata H, eds), pp 39-54. Amsterdam: Elsevier.

Roux S, Escoubet B, Friedlander G, Le Grimellec C, Bertrand I, Amiel C (1989) Effects of lidocaine on sarcolemmal fluidity and cellular cAMP in rat cardiomyocytes. Am J Physiol 256:H422-H427.

Sacchetti B, Lorenzini CA, Baldi E, Tassoni G, Bucherelli C (1999) Auditory thalamus, dorsal hippocampus, basolateral amygdala, and perirhinal cortex role in the consolidation of conditioned freezing to context and to acoustic conditioned stimulus in the rat. J Neurosci 19:9570-9578.

Schafe GE, LeDoux JE (2000) Memory consolidation of auditory Pavlovian fear conditioning requires protein synthesis and protein kinase $\mathrm{A}$ in the amygdala. J Neurosci 20:RC96, 1-5.

Schafe GE, Nadel NV, Sullivan GM, Harris A, LeDoux JE (1999) Memory consolidation for contextual and auditory fear conditioning is dependent on protein synthesis, PKA, and MAP kinase. Learn Mem 6:97-110.

Vazdarjanova A, McGaugh JL (1999) Basolateral amygdala is involved in modulating consolidation of memory for classical fear conditioning. J Neurosci 19:6615-6622.

Wilensky AE, Schafe GE, LeDoux JE (1999) Functional inactivation of the amygdala before but not after auditory fear conditioning prevents memory formation. J Neurosci 19:RC48(1-5).

Zanatta MS, Quillfeldt JH, Schaeffer E, Schmitz PK, Quevedo J, Medina JH, Izquierdo I (1997) Involvement of the hippocampus, amygdala, entorhinal cortex and posterior parietal cortex in memory consolidation. Braz J Med Biol Res 30:235-240. 